\title{
Local Sea Surface Wind, Wind Stress, and Sensible and Latent Heat Fluxes
}

\author{
LuTZ HASSE \\ Institut für Meereskunde, Universität Kiel, Kiel, Germany \\ StUART D. SMith \\ Department of Fisheries and Oceans, Bedford Institute of Oceanography, Dartmouth, Nova Scotia, Canada
}

(Manuscript received 23 January 1996, in final form 4 July 1996)

\section{ABSTRACT}

\begin{abstract}
Parameterization of turbulent wind stress and sensible and latent heat fluxes is reviewed in the context of climate studies and model calculations, and specific formulas based on local measurements are recommended. Wind speed is of key importance, and in applying experimental results, the differences between local and modeled winds must be considered in terms of their method of observation or calculation. Climatological wind data based on Beaufort wind force reports require correction for historical trends. Integrated long-term net turbulent and radiative heat fluxes at the sea surface, calculated from archived data, are consistent with meridional heat transport through oceanographic sections; this lends support to the methods used.
\end{abstract}

\section{Introduction}

The momentum exchange between the atmosphere and ocean-that is, the wind stress on the sea surfaceis a boundary condition for atmospheric and oceanic models and is an essential term for describing coupling in coupled atmosphere-ocean models. This momentum transfer is conditioned by turbulence in the atmospheric surface layer and by sea state; global and regional models cannot describe these complex processes in any detail and must rely on parameterization.

In a surface layer, typically the lower $10 \%$ of the boundary layer, the stress (momentum flux) is nearly constant with height. In a wave boundary layer, nearer to the surface, part of the shear stress is replaced by momentum flux carried by pressure fluctuations to surface waves. Finally, in a surface microlayer typically less than $1 \mathrm{~mm}$ thick, turbulent shear stress is replaced by viscous shear stress. The sea surface is roughened by wind-driven surface waves, and thus the drag coefficient depends on wind speed. The wind shear depends on stratification in the surface layer. Momentum transfer to the waves depends in a complex way on sea state, and so the drag coefficient, or equivalently the roughness length, is also expected to depend on sea state.

Sensible and latent heat fluxes and radiative processes

Corresponding author address: Dr. Stuart D. Smith, Ocean Circulation Division, Bedford Institute of Oceanography, Box 1006, Dartmouth, NS B2Y 4A2, Canada.

E-mail: STU_SMITH@am.dfo.ca transfer heat between the air and the sea. Together with evaporation, precipitation, and runoff, they modify air and water masses at the surface. These air and water masses set up density gradients that drive the circulation of the atmosphere and the oceans.

This paper deals mainly with empirical representation of the wind stress and sensible and latent heat fluxes based on measurements at the local scale. These results can be applied directly to climatological data of local observations. Parameters of GCMs and weather prediction models represent area and time averages that differ from local observations, and these differences must be allowed for either by modifying the parameterization or by separately adjusting grid-scale variables to simulate local variables. Remotely sensed data also represent averages over a footprint area. In both cases, the effective height in the surface layer of modeled or remotely sensed data must be determined.

Wind stress and heat fluxes over ice-covered oceans are quite different from those over open water. The considerable work that has been done on parameterizing fluxes over sea ice is considered to be outside the scope of the present paper.

Section 2 considers the relationship of modeled, remotely sensed, or archived historical winds to the local winds that can be used in empirical formulas to calculate wind stress and sensible and latent heat fluxes. Section 3 discusses recent developments in wind stress formulas, suggesting for climatological calculations a drag coefficient that depends only on wind speed and stability. Section 4 reviews empirical formulas for latent and sensible heat fluxes, pointing out that these formulas should 
be applied to individual samples and not to monthly mean parameters.

The best experimental evidence for the parameterization of wind stress, sensible and latent heat flux, and short- and longwave radiation comes from independent sources and is not necessarily consistent. Section 5 gives an example of a test of consistency for surface fluxes calculated from climatological data, showing that the four parameterized terms in the surface heat budget are compatible with an oceanographic constraint.

There remains a need to measure surface fluxes to test parameterization schemes and to develop algorithms for remote sensing. Because direct eddy correlation measurements of surface fluxes require specialized platforms, they are limited in quantity and mainly restricted to coastal locations. The less direct inertial-dissipation method can be used to estimate surface fluxes from shipboard measurements, but in section 6 it is pointed out that there are some problems in the application of this method that need to be resolved by further research.

\section{Wind}

Fields of wind stress and sensible and latent heat fluxes at an ocean basin scale are determined from wind, temperature, and humidity fields by means of paramaterizations. Any bias that besets the wind field will also affect the derived flux fields. Before we discuss fluxes, it seems appropriate to point to some difficulties that have often affected the use of wind data.

\section{a. What is "surface wind"?}

Both modelers and experimentalists long ago realized the important implications of particular choices in spatial and temporal averaging. In observations, the surface wind is a local variable, taken at a specified height of 10 to $25 \mathrm{~m}$ and averaged over $10 \mathrm{~min}$ (Dobson 1981; Bumke 1995). But in spite of this, the term "surface wind" is much too frequently used to label something different than a 10-min average at a particular location. In a numerical model, the wind at the lowest computational level (not necessarily a single fixed height), corresponding to a wind vector averaged over the area or volume surrounding a grid point, is influenced by the physics of the model. Satellite surface wind retrievals are based on electromagnetic returns from surface waves, averaged over a footprint area and related to a reference height only through the algorithm used. For modeling to benefit from improved experimental flux results and from satellite data, the differences in physics must be understood and the subgrid-scale variability accounted for.

\section{b. Wind climate from Beaufort wind force reports}

Most of the wind speeds in marine climate datasets were originally obtained as Beaufort estimates of wind

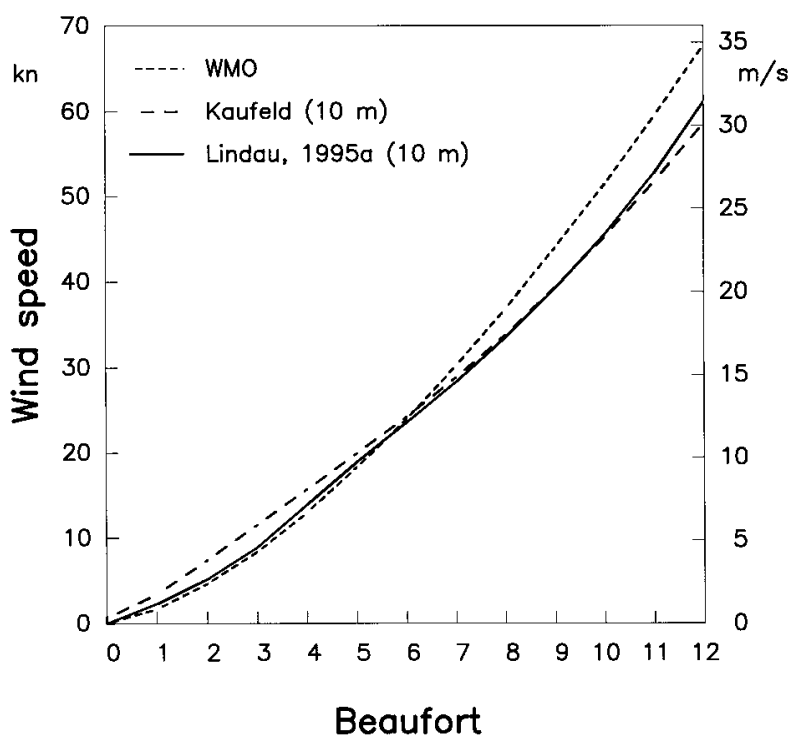

FIG. 1. Comparison of the Beaufort equivalent scales of WMO, Kaufeld (1981), and Lindau (1995a). (Adapted from Lindau 1995a).

force. A "Beaufort equivalent scale" has been used to convert Beaufort force categories into velocities. There are two basic problems with an equivalent scale. First, the Beaufort "wind force" is estimated visually from characteristics produced by the action of the wind. The appearance of the sea state represents physics different than a 10-min average of a local wind at $10-\mathrm{m}$ height. Second, the reporting of Beaufort categories has changed during the transition from sail to steam and with the trend to word using larger, faster ships with observations made from a higher level.

Originally the Beaufort scale was defined by the wind force exerted on a typical sailing ship. Later it was redefined in terms of visible properties of the sea surface. Typically a Beaufort equivalent scale is obtained by comparing Beaufort estimates from passing ships with wind speed measurements on islands or ocean weather ships. Due to natural variability, error variances, and different statistical treatment, such derivations give slightly different results. Most climate data are converted by the official World Meteorological Organization (WMO) scale, code 1100. For research, WMO permits the use of a "Scientific Scale." In an air-sea interaction study of the North Atlantic Ocean based on Bunker's (1976) dataset, Isemer and Hasse (1987) used Kaufeld's (1981) scale, which is similar to the WMO Scientific Scale. This yielded consistent results within rather modest error bands. Lindau (1995a) found that this scale is not suitable for use with the Comprehensive Ocean Atmosphere Data Set (COADS). He derived a new scale (Fig. 1) appropriate for use with COADS from measurements taken on ocean weather ships and observations by passing ships, carefully considering the respective error variances. The scale is similar to WMO code 1100, but with lower wind speeds at higher Beau- 


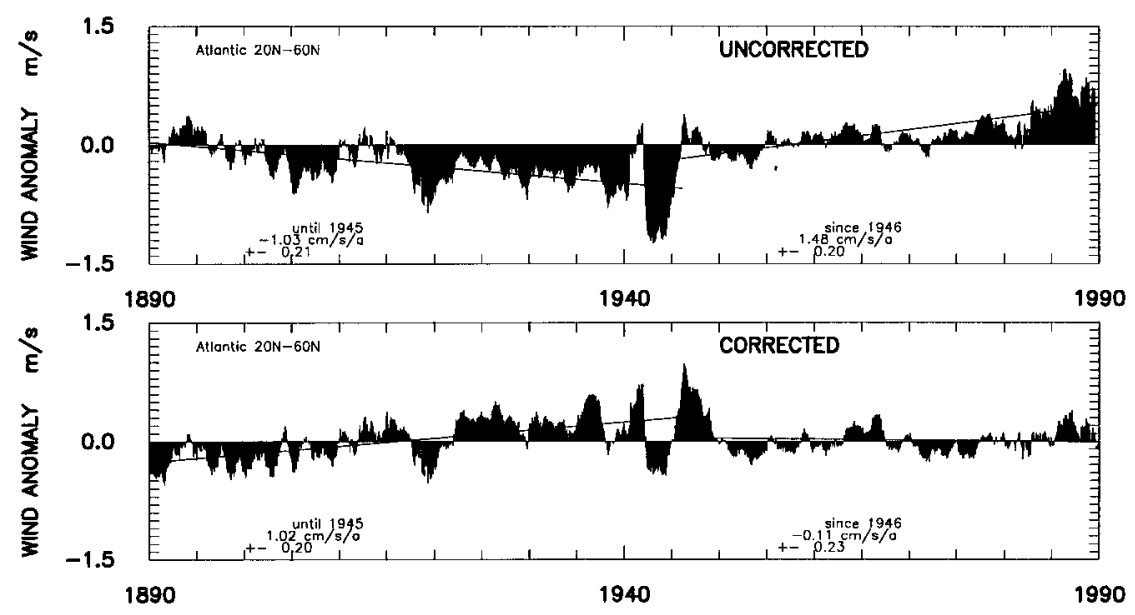

FIG. 2. Variation of mean wind speed over the North Atlantic Ocean: uncorrected (upper panel) and corrected for drift of the Beaufort equivalent scale (lower panel). (From Lindau 1995b.)

fort forces. The new scale optimally translates Beaufort forces into wind speeds; hence, the error variances of the Beaufort estimates need to be considered when deriving statistics from these data.

In work with climatological wind data, a correction is needed to eliminate spurious trends due to the transition from sail to steam and the trend toward using larger ships with observations made from a higher level. Sailing routes where older data are more concentrated were not the same as modern shipping lanes. A mix of uncorrected old and new data could result not only in spurious climate drift, but also in spurious wind and stress gradients, affecting operations like divergence or curl. A drift of input data could also induce spurious trends in the results of reanalysis projects. Peterson and Hasse (1987) demonstrated that the Beaufort scale has shifted from the time of sailing ships to today. A timedependent correction has been derived by assuming that the average relationship between surface wind and geostrophic wind (from sea level air pressure gradients) has not changed (Lindau 1995b). With the Beaufort scale referred to a common base period, it is found that the

TABLE 1 . The ratio $U_{\text {obs }} / U_{\text {geo }}$ of observed surface wind to analyzed geostrophic wind speed for ranges of onshore and offshore distances from the coastline. In this study, ship observations from the semienclosed Baltic Sea have been used, so that fetch over water was limited both upwind and downwind of the observing point. (Adapted from Karger 1995.)

\begin{tabular}{ccccccc}
\hline \hline $\begin{array}{c}\text { Offshore } \\
\text { distance } \\
(\mathrm{km})\end{array}$ & $1-5$ & $5-10$ & $10-20$ & $20-30$ & $30-50$ & $>50$ \\
\cline { 2 - 7 } & 0.52 & 0.56 & 0.59 & 0.62 & 0.65 & 0.66 \\
$1-5$ & 0.57 & 0.59 & 0.62 & 0.66 & 0.69 & 0.70 \\
$5-10$ & 0.61 & 0.63 & 0.66 & 0.70 & 0.74 & 0.75 \\
$10-20$ & 0.65 & 0.68 & 0.72 & 0.76 & 0.79 & 0.80 \\
$20-30$ & 0.69 & 0.73 & 0.76 & 0.82 & 0.85 & 0.86 \\
$30-50$ & 0.70 & 0.74 & 0.78 & 0.84 & 0.86 & 0.88 \\
$>50$ & & & & & & \\
\hline
\end{tabular}

wind climate of the North Atlantic Ocean has not changed appreciably during the last century (Fig. 2).

\section{c. Coastal effects}

The aerodymamic roughness of land surfaces is much greater than that of the sea, and this results in a change of the wind speed near the shore, both for onshore and offshore winds. A study of surface wind over the Baltic Sea has been made to empirically quantify this effect (Karger 1995). The ratios of observed wind to geostrophic wind (determined from pressure observations at sea level) are given in Table 1. For better comparison, the driving force of the pressure field at sea level is expressed as a geostrophic wind rather than a pressure gradient. The results show that the change of roughness (and stability) at the land-sea transition affects both onshore and offshore flow. The transition from higher speeds over sea to lower speeds over land is mainly concentrated in the first $10 \mathrm{~km}$ from shore.

The spatial variation of wind speed is important in studies of wave generation near shore. From a number of flights at 50-m height in offshore winds during the Canadian Atlantic Storms Experiment (CASP), Smith and MacPherson (1987) found that the wind speed $U_{50}$ at the shoreline was on average $73 \%$ of the wind speed offshore and that the average $e$-folding scale was 9.3 $\mathrm{km}$, so that empirically

$$
U_{50}(X) \approx U_{50}(50 \mathrm{~km})\left(1-0.27 \mathrm{e}^{-X / 9.3 \mathrm{~km}}\right),
$$

where $X$ is the fetch downwind from the shoreline. Perrie and Toulany (1995) have inverted the CASP fetch-limited wave relations to infer the variation of wind speed with fetch in terms of spectral wave parameters. The Baltic Sea and CASP data agree that most of the effect is within $10 \mathrm{~km}$ and that the decay with distance from shore is approximately exponential. From wave and wind measurements during CASP, Dobson et al. (1989) 
derived laws for wave growth with fetch that match and extend the results of Donelan et al. (1985), but differ from the Joint North Sea Wave Project (JONSWAP) formulas (Hasselmann et al. 1973). The difference can be resolved by allowing for the variation of wind speed with fetch, which was not included in the original JONSWAP analysis.

\section{Parameterization of wind stress}

\section{a. Drag coefficient}

Wind stress is most commonly determined from surface-layer variables by the bulk aerodynamic formula

$$
\tau=\rho C_{10} U_{10}^{2},
$$

where the subscript 10 indicates a reference height of $10 \mathrm{~m}$. The drag coefficient $C_{10}$, which represents the influence of turbulence on the relation between wind and stress, depends mainly on stability and wind speed and/or sea state, and itself needs to be parameterized. We assume that the necessary information is available either from surface observations or other data with similar characteristics.

The drag coefficient is meant to represent the total air-sea momentum flux. Near the surface, the flux is partitioned into wave-supported and turbulent components. The wave influence decays exponentially with height $z$ as $e^{-k z}$, where $k$ is wavenumber of the dominant waves, while the influence of stability on the wind speed profile increases with height. Thus it is reasonable to treat the two influences as if they were independent.

\section{b. Roughness length}

The roughness length $z_{o}$ is often used as an alternate to the drag coefficient. It is defined through the wind profile in the constant stress layer, which is logarithmic under neutral conditions:

$$
U(Z)=\left(u_{*} / \kappa\right)\left[\ln \left(z / z_{o}\right)\right] .
$$

Here, $u_{*}=(\tau / \rho)^{1 / 2}$ is the friction velocity and the traditional value of the von Karman constant $\kappa=0.4$ remains valid for the sea surface, although a slightly lower value of 0.39 is now considered appropriate for rougher surfaces such as grassland (Frenzen and Vogel 1995). In stable or unstable stratification, the profile is described by empirical flux-gradient relations based on Monin-Obukhov similarity theory, which is not reproduced here (see Berkowicz and Prahm 1982; Panofsky and Dutton 1984; Isemer and Hasse 1987; Smith 1988; Kagan 1995; Gulev 1995). The roughness length and the neutral drag coefficient are uniquely related through (2) and (3):

$$
\begin{aligned}
c_{10 N} & =\left[\kappa / \ln \left(10 \mathrm{~m} / z_{o}\right)\right]^{2}, \\
z_{o} & =10 \mathrm{~m}\left\{e^{-\kappa C_{10 N}^{-1 / 2}}\right\},
\end{aligned}
$$

so that specifying one also determines the other.
Over solid surfaces, $z_{o}$ is related to the height of roughness elements. Here, the surface fluxes can be estimated from profiles of mean wind, temperature, and humidity measured at two or more heights (e.g., Berkowicz and Prahm 1982).

In the wave boundary layer (lowest part of the surface layer) over the sea where the wave-supported stress is significant (especially during the growth of surface waves), the turbulent stress is not constant with height and the neutral wind profile no longer follows $(3) ; z_{o}$ can still be formally defined for a constant stress layer above the wave boundary layer, but the physical meaning of $z_{o}$ as an effective roughness parameter of the sea is unclear. In our judgement, this is a barrier to the general use of $z_{o}$ in dimensional arguments, as in the derivation of the "Charnock relation" (Charnock 1981). However, $z_{o}$ does offer certain mathematical advantages in practical work. Where a wave boundary layer exists, it is safer to think of $z_{o}$ as a function of the neutral drag coefficient than as a physical property of the surface.

\section{c. Wave age and wind stress}

The dependence of the momentum transfer or the drag coefficient on sea state was recognized early, but remains a matter of research. Smith (1980) found different dependences of drag coefficient with wind speed for limited and unlimited fetch. It is difficult, however, to give a reliable numerical formulation for the process. From a theoretical point of view, $u_{*}$ is preferred for normalization, although wind speed as the normalizing variable does have the advantages of lesser error variance and more universal availability. Smith et al. (1992) fitted nondimensional roughness $z_{o *}$ (in spite of the above caveats) to wave age in the form

$$
z_{o *} \equiv g z_{o} / u_{*}^{2}=0.48\left(c_{p} / u_{*}\right)^{-1}
$$

to data obtained from a platform in the North Sea $9 \mathrm{~km}$ off the Dutch coast in the Humidity Exchange over the Sea (HEXOS) Program. This follows the expectation of most researchers in the field that the momentum transfer to the sea, expressed by a drag coefficient, is less effective with increasing wave age, expressed by the ratio $c_{p} / u_{*}$ of wave phase velocity to wind speed. Unfortunately the relative variability of $u_{*}$ (i.e., the variability of $\ln u_{*}$ ) was greater than that of $c_{p}$ in HEXOS, as in other field datasets. Hence, in a relation such as (5), a spurious correlation of variables normalized with $u_{*}$ cannot be ruled out (Smith et al. 1992). Any other normalizing variable (such as wind speed) that is itself closely correlated with $u_{*}$ also gives rise to the same possibility. Perrie and Toulany (1990) demonstrated this principle by working out an example in a related field; they pointed out a need for significant correlation in the dimensional variables. Perrie and Toulany (1995) have proposed a formula for the friction velocity as a function of the wave age and slope.

Perrie and Wang (1995) applied (5) in a spectral wave 
model, coupling the wind stress to the wave age. This has the effect of increasing the stress and the initial growth rate for young waves. This alleviates a tendency of the state-of-the-art Wave Model (WAM) to underestimate peak wave height during high-sea conditions, while if the wind speed is not strong, the waves quickly mature and the difference between the coupled and uncoupled WAMs is negligible. This lends some independent support to the use of (5), but does not test the physical and statistical arguments used in its derivation.

At the HEXOS site in a depth $\mathrm{h}=18 \mathrm{~m}$ of water, the phase velocity of surface waves was limited to a maximum value $(g h)^{1 / 2}=13.3 \mathrm{~m} \mathrm{~s}^{-1}$. The HEXOS data with younger wave ages were mainly at wind speeds higher than $13 \mathrm{~m} \mathrm{~s}^{-1}$, where the wave age was limited more by depth than by fetch or by wind duration. Donelan et al. (1993) showed that a larger quantity of data for fetch-limited (deep water) waves in Lake Ontario, covering a slightly greater range of wave ages, behaved in a similar way to the HEXOS data. We believe that (5) describes the general pattern of the wave influence, but the magnitude remains uncertain.

\section{d. Wind stress and wave age in the presence of swell}

The ubiquitous coexistence of wind sea and swells from different directions makes the problem of the influence of waves on wind stress even more complicated. Although the direct momentum exchange of swell with the wind is negligible, wind-driven seas exchange momentum with the air above and also exchange energy and momentum with the swell in a complex way. In a natural situation, it is exceedingly difficult to differentiate between wind seas and swell (Dobson et al. 1994). Smith et al. (1992) derived (5) from a subset of the HEXOS data for which a single wave spectral peak was found; more often, the wave spectrum had more than one peak.

The dilemma that we face here is somewhat alleviated by a correlation between wind speed and wave age: in any given dataset, the highest observed winds generally represent transient events, associated with "young" waves. The linear relation of Smith (1980) for unlimited fetch and winds above $4 \mathrm{~m} \mathrm{~s}^{-1}$,

$$
10^{3} C_{10 N}=0.61+0.063 U_{10 N}\left(\mathrm{~m} \mathrm{~s}^{-1}\right) \text {, }
$$

has a higher slope than Smith (1988) obtained from (4) by setting $a=0.011$ in the Charnock relation

$$
z_{o}=a u_{*}^{2} / \mathrm{g} .
$$

This "higher-than-Charnock" increase of $C_{10 N}$ with wind speed can be taken to represent a presumed trend toward the nonequilibrium of the wind and sea at higher wind speeds, resulting in younger wave age and higher roughness. Thus, in a general way, an influence of wave age is built into (6) in relation to (7) and (4). Large and Pond (1981) proposed a constant drag coefficient for light winds,

$$
10^{3} C_{10 N}=1.14 \text { for } U_{10 N}<10 \mathrm{~m} \mathrm{~s}^{-1},
$$

and a linear relation for moderate and strong winds,

$$
\begin{gathered}
10^{3} C_{10 N}=0.49+0.065 U_{10 N}\left(\mathrm{~m} \mathrm{~s}^{-1}\right) \\
\quad \text { for } 10<U_{10 N}<26 \mathrm{~m} \mathrm{~s}^{-1} .
\end{gathered}
$$

Equations (6) and (8) agree with each other, within experimental uncertainty that results from the influence of sea state and possibly other parameters, and the scatter in either Smith's (1980) or Large and Pond's (1981) datasets precludes establishing a clear preference for one form or the other (Fig. 3).

At very low wind speeds, below about $2-3 \mathrm{~m} \mathrm{~s}^{-1}$, no waves are generated, and it seems reasonable to argue that the stress should not be less than for an aerodynamically smooth flow in which

$$
U(z) / u_{*}=(1 / \kappa) \ln \left(0.11 v / u_{*}\right),
$$

where $v \approx 14 \times 10^{-6} \mathrm{~m}^{2} \mathrm{~s}^{-1}$ is the kinematic viscosity of air and the numerical value 0.11 for turbulent flow over a flat plate is that commonly adopted in meteorology (e.g., Wippermann 1972; Smith 1988). This smooth flow constraint causes the drag coefficient to increase with decreasing wind speed below about $3 \mathrm{~m}$ $\mathrm{s}^{-1}$.

The above discussion of drag coefficients relates to the local scale. For use with climatological datasets, these can be applied after suitably eliminating errors in deriving wind speeds from Beaufort force reports, or influences of height and flow distortion on ships' anemometers.

For use in numerical models, the influence of subgridscale variations needs to be considered explicitly. For the northwest Atlantic, Gulev (1994) found an average ratio (sampling with the classical method, with monthly averaging) of 1.49, and for the subtropical Pacific, Hanawa and Toba (1987) found a ratio of 1.45. In a detailed analysis of the effects of temporal and spatial averaging for the North Atlantic Ocean, Gulev (1997) found that "sampling" estimates in general gave 20\%-60\% higher fluxes values than "classical" estimates.

\section{Parameterization of latent and sensible heat fluxes}

The turbulent sensible $(H)$ and latent heat fluxes (LE) can be estimated from routine local observations of wind speed $(U)$, sea surface temperature $\left(T_{s}\right)$, air temperature $(\mathrm{T})$, and specific humidity $\left(q_{10}\right)$ at a reference height (here taken at $10 \mathrm{~m}$ ) if the sensible heat flux coefficient (Stanton number) $C_{H}$ in the bulk formula

$$
H=\rho c_{p} C_{H} U_{10}\left(T_{s}-T_{10}\right)
$$

and the evaporation coefficient (Dalton number) $C_{E}$ in

$$
\mathrm{LE}=\rho L C_{E} U_{10}\left(0.98 q_{s}-q_{10}\right)
$$

are known, where $\rho$ is density, $c_{p}$ is specific heat, $L$ is the latent heat of evaporation of water, and $q_{s}$ is the 


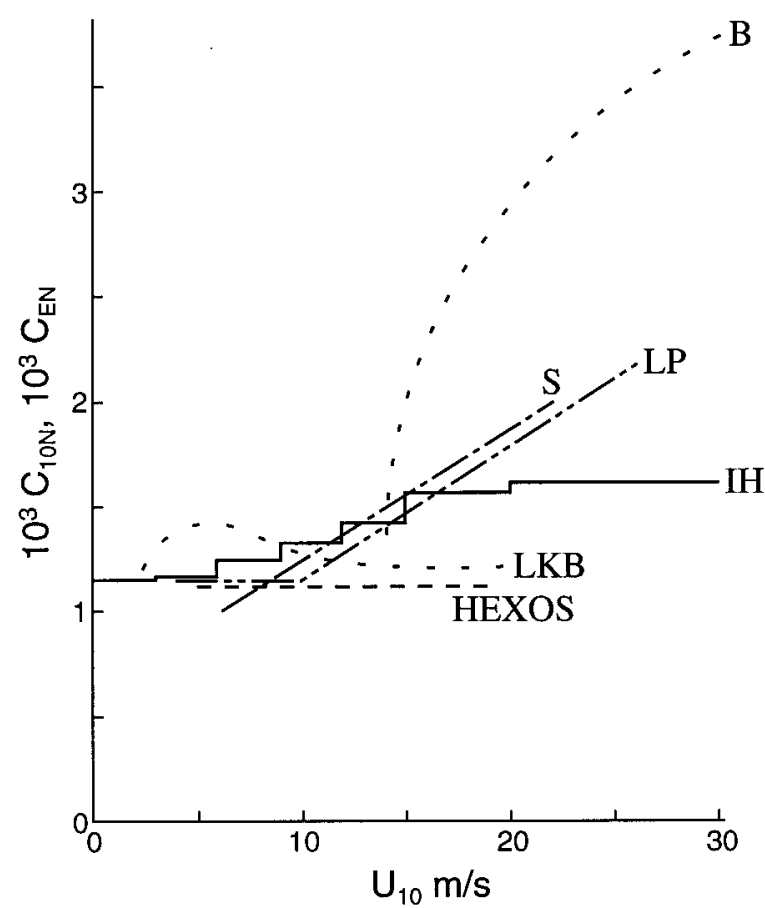

FIG. 3. Variation of evaporation coefficient $C_{E}$ with wind speed. Bortkovski's (1987) hypothesized rise of evaporation coefficient due to evaporation of spray (dotted line B), the Liu et al. (1979) surface renewal model (dotted line LKB), neutral evaporation coefficients used by Isemer and Hasse (1987) and by Lindau (1996), (solid line $\mathrm{IH}$ ) and the HEXOS result (12) (dashed line). Also shown are neutral drag coefficients of Smith (1980) (s) and of Large and Pond (1981) (LP).

saturation humidity at temperature $T_{s}$. The factor 0.98 arises from a reduction of vapor pressure by the salinity of seawater and would be 1.0 for freshwater. As discussed above for wind stress, (10) and (11) apply to local variables. To model gridded flux fields, the relationships between local quantities and values at grid points must also be considered. In (10), potential temperatures should be used in principle, but the difference $\left(\approx 0.1^{\circ}\right.$ at 10 -m height $)$ is usually insignificant.

\section{a. Evaporation coefficient}

The variation of $C_{E}$ with wind speed has been a matter of debate because with increasing wind speed, additional evaporation from airborne spray droplets might be expected. Model predictions for the evaporation coefficient at sea (Fig. 3) illustrate a rather large range of possibilities. Bortkovskii (1987) and others hypothesized that evaporation of spray droplets would cause a rapid increase in the effective evaporation coefficient at wind speeds above $14 \mathrm{~m} \mathrm{~s}^{-1}$. The surface renewal model of Liu et al. (1979) did not include droplet evaporation. Direct eddy correlation measurements of water vapor flux were not available above about $14 \mathrm{~m} \mathrm{~s}^{-1}$, for the very reason that accumulation of salty spray droplets interfered with the operation of fast-response humidity sensors. Most datasets had average values of $C_{E N}=$ 0.0011 to 0.0012 , except that higher values for sites where surf zones were upwind of the sensors gave qualitative support to the idea that spray droplets would enhance the evaporation rate (Smith 1989).

In HEXOS, with aspirated shields protecting the fast humidity sensors from damage by spray-laden marine air, turbulent water vapor fluxes were measured at wind speeds up to $19 \mathrm{~m} \mathrm{~s}^{-1}$ (DeCosmo et al. 1996). A mean value of

$C_{E N}=0.00112 \pm 0.00024$ (standard deviation)

was obtained, and there was no significant increase with wind speed (Fig. 4). Values of $C_{H N}=0.00114 \pm$ 0.00035 were similar but had more scatter, for winds up to $23 \mathrm{~m} \mathrm{~s}^{-1}$. The rise of the HEXOS drag coefficients and of derived surface roughness $z_{o}$ with wind speed, as well as the near-independence of $C_{E}$ and $C_{H}$, implies that the effective values of the thermal and humidity roughness lengths decrease with wind speed, more or less as predicted by the surface renewal model of Liu et al. (1979). From HEXOS field and laboratory experiments, it was inferred that there is a negative feedback: in a "droplet evaporation layer" close to the surface, the evaporating droplets modify the gradients and reduce the turbulent flux, partially offsetting the increased latent heat flux by evaporation of droplets. Also, in earlier studies, the formation of droplets was overestimated.

Until recently there have been no measurements of evaporation at very low wind speeds. Bradley et al. (1991), from eddy correlation measurements of sensible and latent heat fluxes during a cruise in the tropical Pacific Ocean, reported that $C_{E N}$ rose somewhat more at low wind speeds $\left(<3 \mathrm{~m} \mathrm{~s}^{-1}\right)$ than would be expected from laboratory results for a smooth surface. At these low wind speeds, stratification has a large influence on the profiles and the exchange coefficients.

Miller et al. (1992) reported on a revision of evaporation from the sea surface in the European Centre for Medium-Range Weather Forecasts model that significantly improved the simulation of both climate and weather in tropical and subtropical regions. A smoothsurface constraint, based on laboratory results for shear flow over smooth surfaces, caused $C_{E}$ to rise with decreasing wind speed for $U<3 \mathrm{~m} \mathrm{~s}^{-1}$. Allowance was also made for subgrid-scale convective winds that can drive sensible and latent heat fluxes even when gridscale or vector-averaged winds are vanishingly small.

\section{b. Sensible heat flux coefficient}

The influence of stability on $C_{H}$ and $C_{E}$ can be calculated using Monin-Obukhov similarity theory and empirical relations between turbulent fluxes and vertical gradients based on experiments over land (see Panofsky and Dutton 1984). To verify these results over the sea, Hasse et al. (1978) made an indirect test with open- 


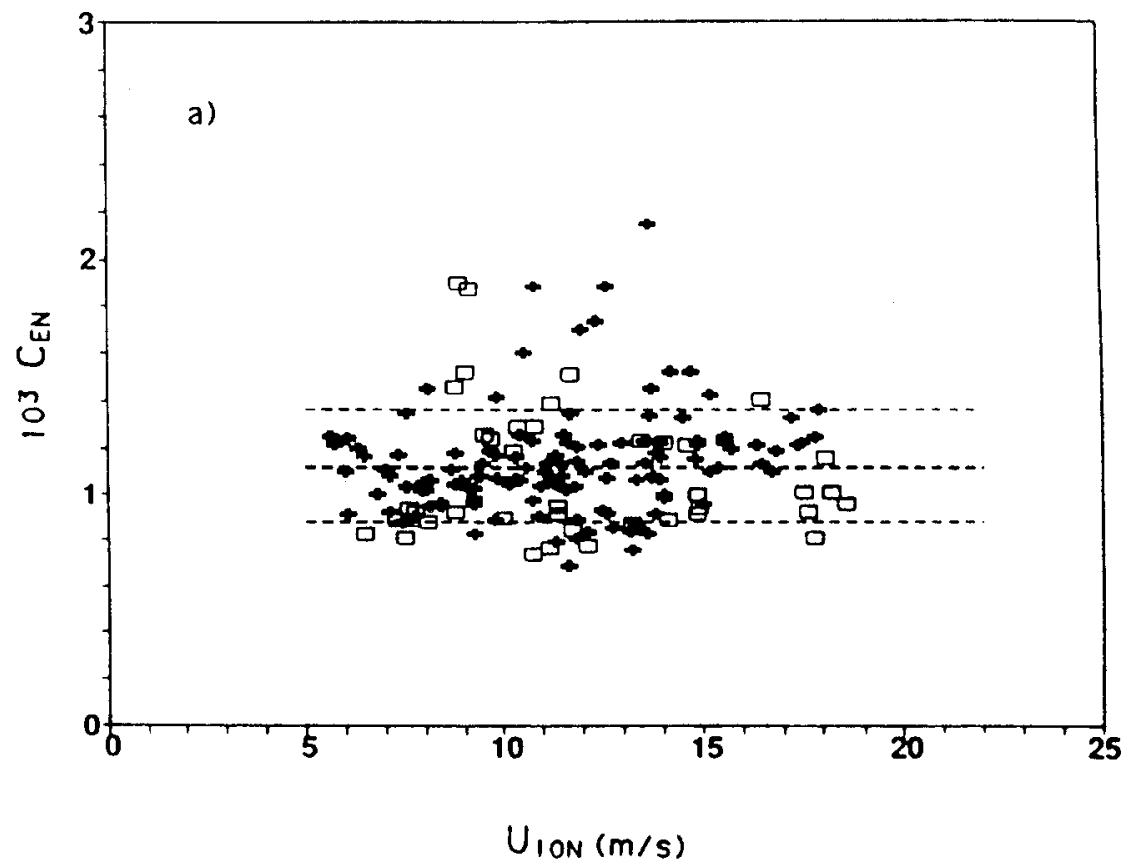

FIG. 4. HEXOS evaporation coefficients. Heavier dashed line is (12), and lighter dashed lines are \pm standard deviation of the data. (From DeCosmo et al. 1996.)

ocean data from the Global Atmospheric Research Program (GARP) Atlantic Tropical Experiment and found no systematic deviations. Smith (1988) interpreted his open-sea (Smith 1980) data to set $C_{H 10 N}=0.0010$ in near-neutral conditions and with empirical flux-gradient relations derived from the 1968 Kansas experiment over land, and tabulated the dependence of $C_{H}$ on stability as a function of the sea-air virtual potential temperature difference (Fig. 5). Evaporation coefficients are expected to follow a similar dependence on stratification. The influence of stability is strongest at low wind speeds. On average, the marine surface layer is slightly unstable, and so average transfer coefficients are larger than the values adjusted to neutral stratification that we use for comparison.

Typically at sea, $\Delta q=0.98 q_{s}-q_{10}$ is quite large and $\Delta T=T_{s}-T_{10}$ is small and of changing sign. This tends to make determinations of $C_{H}$, often the ratio of small experimental quantities, less reliable than those of $C_{E}$. Except in polar regions, the transfer of latent heat from the world's oceans is generally a much larger component of the surface heat budget than that of sensible heat. Temperature gradients, on the other hand, generally have a greater influence on atmospheric stability.

Since heat flux coefficients are less well established, it is reasonable to assume that the two turbulent fluxes behave similarly and to take $C_{H}$ as a constant fraction of $C_{E}$. We know from direct and IR measurements that there is often a cool film at the liquid side of the interface, which is evidence of an aqueous diffusive thermal sublayer. Heat and vapor fluxes have different resistances at the interface: water vapor has to pass through a diffusive sublayer only at the air side of the interface, while heat flux must pass through two sublayers. Also, the molecular diffusivities in air are different for vapor and heat. Although the turbulent part of the transport should not be too different, we would expect the extra resistance in the water sublayer to make $C_{H}$ slightly smaller than $C_{E}$. Isemer and Hasse (1987) selected a ratio of $C_{H} / C_{E}=0.94$, based mainly on experimental results from the open sea (e.g., Dunckel et al. 1974).

\section{c. Sampling and classical monthly heat fluxes}

So far we have looked only at the estimation of hourly local fluxes. Denoting monthly means by angle brackets $(\langle\rangle)$ and deviations from the means by primes ('), and expanding (11), the monthly mean heat flux calculated from individual samples by the sampling method is

$$
\begin{aligned}
\langle\mathrm{LE}\rangle= & \left\langle\rho L C_{E} U_{10}\left(0.98 q_{s}-q_{10}\right)\right\rangle=\left\langle C_{E} U_{10} \Delta Q\right\rangle \\
= & \left\langle C_{E}\right\rangle\left\langle U_{10}\right\rangle\langle\Delta Q\rangle+\left\langle C_{E}\right\rangle\left\langle U_{10}^{\prime} \Delta Q^{\prime}\right\rangle \\
& +\left\langle U_{10}\right\rangle\left\langle C_{E}^{\prime} \Delta Q^{\prime}\right\rangle+\langle\Delta Q\rangle\left\langle C_{E}^{\prime} U_{10}^{\prime}\right\rangle \\
& +\left\langle C_{E}^{\prime} U_{10}^{\prime} \Delta Q^{\prime}\right\rangle,
\end{aligned}
$$

with $\Delta Q=\rho L\left(0.98 q_{s}-q_{10}\right)$. Sensible heat flux can be separated in a similar way. At a time when data handling required a great deal of labor and computing resources were limited, the classical method was to first calculate monthly averages of each variable, so that only the first of the above five terms was retained. Once the input data have been averaged, the remaining terms are lost. 


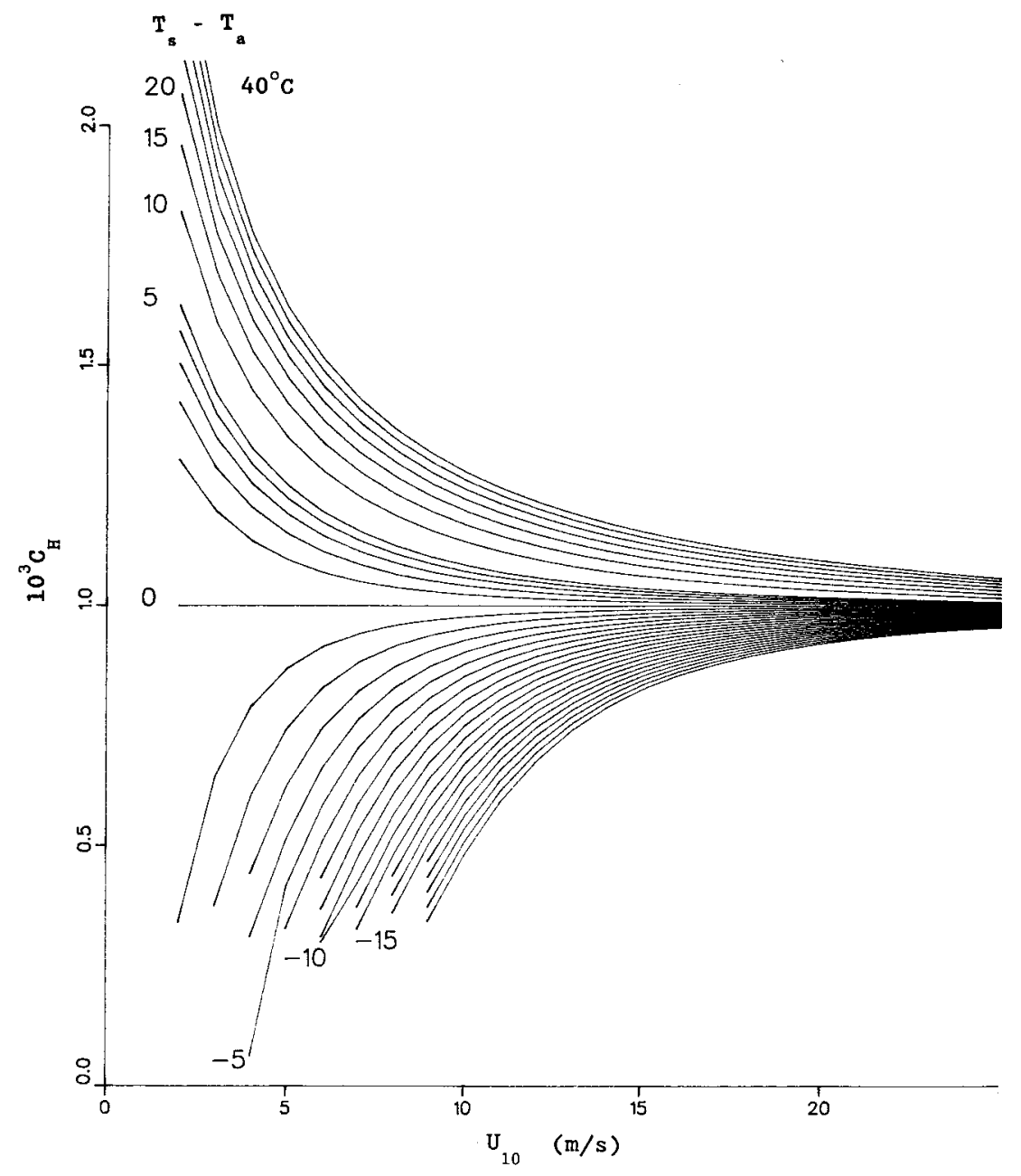

FIG. 5. Variation of sensible heat transfer coefficient with sea-air virtual temperature difference using "Kansas" flux-gradient relations. (From Smith 1988.)

Bunker (1976) was a pioneer in calculating surface flux climatology by the sampling method. Gulev (1994) treated both temporal and spatial averaging, while most other authors have examined temporal averaging to find relations between the classical and sampling methods. For the midlatitude western Atlantic, the sampling method gave higher values than the classical method used with monthly means by a factor of 1.43 for $H, 1.27$ for $E$, and 1.49 for $\tau$. There is an annual variation: the factors vary between 1.15 and 1.35 for $E$, and 1.4 and 1.6 for $\tau$. The factors for 400- (800) km diameter spatial averaging are 1.31 (1.69) for $H, 1.38$ (1.81) for $E$, and 1.26 (1.55) for $\tau$. Gulev (1997) extended this work to cover the entire North Atlantic based on COADS. The ratios of surface fluxes calculated by the sampling and classical approaches varied considerably; typically the fluxes were underestimated by the classical method. For ocean weather station (OWS) L $\left(57^{\circ} \mathrm{N}, 20^{\circ} \mathrm{W}\right)$, Josey et al. (1995) found that the classical method overestimated monthly sensible and latent heat fluxes by up to 8 and $16 \mathrm{~W} \mathrm{~m}^{-2}$, respectively (Fig. 6). For tropical oceans, where the weather tends to be less variable, Esbensen and McPhaden (1996) found the underestimation of evaporation and sensible heat flux by the classical method was typically only about $10 \%$ in the ITCZ and less for the trade winds, in agreement with Hanawa and Toba (1987), who found that the classical method overestimated evaporation by about $5 \%$ for the subtropical western Pacific.

For different climates, the terms in (13) cannot be expected to have a fixed relation to each other nor to classical estimates, and so it is not possible to account for the missing terms in a general way by simply altering the value of $C_{E}$. With the present powerful data handling tools it is no longer difficult to use the sampling method, but when referring to earlier climatological studies of surface fluxes, it is important to ascertain whether the sampling or the classical method was used.

\section{Consistent parameterizations}

Parameterizations for turbulent and radiative air-sea fluxes have been based on measurements at the local 

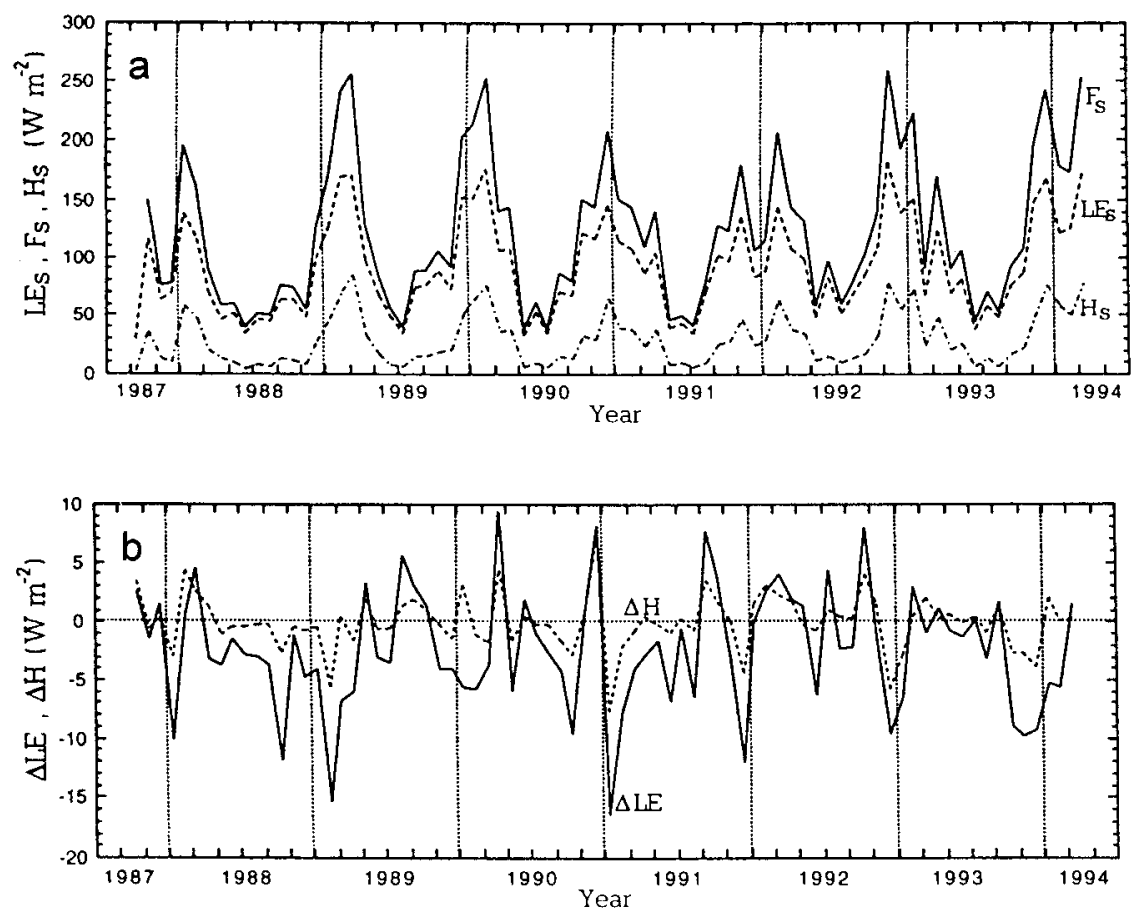

FIG. 6. (a) Monthly mean latent ( $\mathrm{LE}_{s}$, dashed line), sensible ( $H_{s}$, dashed and dotted), and total turbulent $\left(F_{s}\right.$, solid line) heat flux at OWS L $\left(57^{\circ} \mathrm{N}, 20^{\circ} \mathrm{W}\right)$ by the sampling method. (b) Monthly difference between sampling and classical mean latent ( $\Delta \mathrm{LE}$, solid line) and sensible ( $\Delta H$, dashed line) heat fluxes. (From Josey et al. 1995.)

scale. By their very character, they are simplifications that are intrinsically less than perfect. Parameterizations for the different fluxes have been derived independently and are not necessarily consistent. Unavoidable experimental errors can result in a bias in the derived coefficients, and small biases are especially felt in determining the net air-sea heat flux where two large opposing terms - insolation and latent heat flux - are of similar magnitude. This poses a problem, for example, in the integration of the net surface flux to estimate heat transport by ocean currents.

\section{a. An oceanic constraint to air-sea heat exchange}

In the global long-term mean, the net atmospheric heat input into the ocean nearly vanishes. Local or regional imbalances must be compensated by heat advection, as ocean currents help to transport heat from the Tropics toward the temperate and higher latitudes. In the long term, where heat storage can be neglected, heat transport in the ocean can be determined in principle from the area integral of net surface heat flux. This estimate is dependent on the choice of paramaterizations. Uncertainties in estimating the surface flux components generally make such determinations insufficiently precise to derive the ocean meridional heat transport. Instead, oceanic sections can be used to test and improve (if necessary) the surface flux calculation by adjusting the bulk formulas to make long-term results by the two methods consistent. Isemer et al. (1989) used an inverse technique with Bryden and Hall's (1980) meridional heat flux at $24^{\circ} \mathrm{N}$ to optimize the parameterizations for use with Bunker's North Atlantic dataset. The result was encouraging in that the adjustment needed to make the surface fluxes agree was only $20 \%-40 \%$ of the estimated error in the parameterization.

\section{b. Meridional heat transport of the Atlantic Ocean}

With the increased amount of data now available from COADS, Lindau (1997) has made a new calculation of surface fluxes for the whole Atlantic Ocean north of $30^{\circ} \mathrm{S}$, making the historical wind data consistent and recalibrating the Beaufort scale, as discussed above. Unfortunately there is still some uncertainty in the choice of parameterization schemes. Among the four components of surface heat flux, the least well established appears to be the longwave radiation (Gulev 1995). Longwave radiation was parameterized according to Gilman and Garrett (1994), based on their results in a study of the heat exchange of the Mediterranean Sea. However, the Mediterranean Sea presents a complex situation that may not be typical of the open ocean. The parameterization for shortwave radiation under clear and cloudy skies was taken from Malevsky et al. (1992), based on a large set of oceanic observations, instead of from Reed (1977), which was based on coastal and island stations. Malevsky et al. also have the advantage 

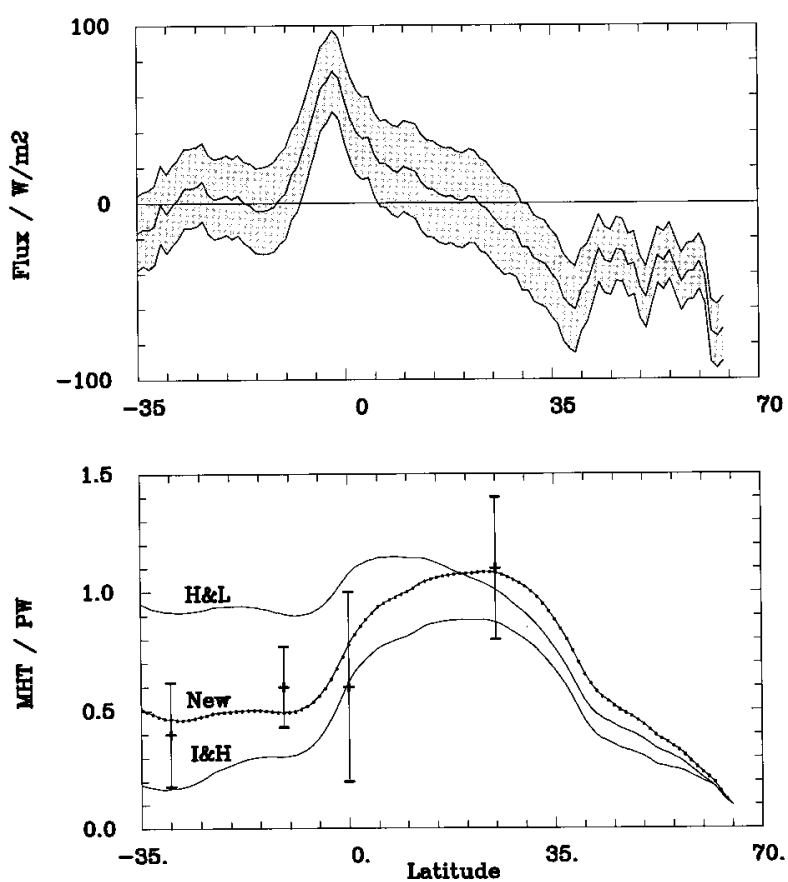

FIG. 7. Net air-sea heat flux and oceanic meridional heat transport of the Atlantic Ocean. (a) Zonal mean net air-sea heat flux per unit area in $\mathrm{W} \mathrm{m}^{-2}$ vs latitude. The error bands (shaded) are based on the error estimates of Isemer and Hasse (1987). (b) In order to compare the net air-sea heat flux with evidence from oceanographic sections, the oceanic meridional heat transport is calculated by integration of net air-sea heat flux, starting at $65^{\circ} \mathrm{N}$, taking into account the width of the ocean: dotted line-new calculation (Lindau 1996); H\&LHastenrath and Lamb (1978); I\&H-Isemer and Hasse (1987). These authors originally used different databases; for comparison, each of their parameterizations was applied to the COADS. Meridional heat transports from oceanographic sections are shown with error bars at $30^{\circ} \mathrm{S}$ (Holfort 1994), $11^{\circ} \mathrm{S}$ (Speer et al. 1996), $0^{\circ}$ (Wunsch 1984), $25^{\circ} \mathrm{N}$ (Bryden and Hall 1980), and $65^{\circ} \mathrm{N}$ (Aagaard and Greisman 1975). Oceanic meridional heat transport (MHT) is given in PW $\left(=10^{15} \mathrm{~W}\right)$ vs latitude. (After Lindau 1996.)

of modeling variations of atmospheric transmission (see Gulev 1995 for details of their methods). The transfer coefficients for latent heat fluxes $C_{E}$ were taken from Isemer and Hasse (1987, their Table 4), and $C_{H}$ was taken to be $0.94 C_{E}$. A detailed account of the set of parameterizations is given by Lindau (1997).

The results of Lindau's calculation of the net air-sea heat exchange are given as zonal averages in Fig. 7a. In the long-term mean, this exchange must be balanced by oceanic advection. Since there are only a few eastwest oceanographic temperature and current sections, a direct comparison is not conclusive. Instead, the meridional oceanic heat flux is calculated from the surface fluxes by integration (Fig. 7b). The integration was started at $65^{\circ} \mathrm{N}$ with a value of $0.1 \mathrm{PW}$ northward (Aagaard and Greisman 1975). [Gulev and Tikhonov (1989) advocated a value of $0.3 \mathrm{PW}$; the difference of $0.2 \mathrm{PW}$ would be added to the northward heat transport at all latitudes.] The general pattern is northward transport at all latitudes, with a peak at $22^{\circ} \mathrm{N}$, where the sign of the net flux reverses in Fig. 7a.

Heat transport from oceanographic sections at $30^{\circ} \mathrm{S}$ (Holfort 1994), $11^{\circ} \mathrm{S}$ (Speer et al. 1996), $25^{\circ} \mathrm{N}$ (Bryden and Hall 1980), and inferred for the equator (Wunsch 1984) all agree with the transports from Lindau's new integration of surface flux within half of their error bars. The integration with Isemer and Hasse's (1987) parameterization also agrees within the error bars of the oceanographic sections and would agree better if the integration had been started with the higher Gulev and Tikhonov value of $0.3 \mathrm{PW}$ at $65^{\circ} \mathrm{N}$. No modification of the flux coefficients was needed to achieve consistency between the independent surface and oceanographic flux calculations. The balance of long-term mean heat loss of the ocean to the atmosphere in the Atlantic north of $35^{\circ}$ with independently determined oceanographic advection, without recourse to adjustment of the surface flux parameterization, implicitly supports the choices made, including the use of the new Beaufort equivalence scale. The Atlantic Ocean spans a variety of climates; specific comparisons have been shown for regions from $0^{\circ}$ to $30^{\circ} \mathrm{S}$, from $0^{\circ}$ to $25^{\circ} \mathrm{N}$, and from $25^{\circ}$ to $65^{\circ} \mathrm{N}$. Hence, this set of parameters should be applicable to other oceans too. The parameterization used by Hastenrath and Lamb (1978) results in transports that are too high at $0^{\circ}$ and $30^{\circ} \mathrm{S}$, but there is good agreement at $25^{\circ} \mathrm{N}$ - that is, in the net surface fluxes between $25^{\circ}$ and $65^{\circ} \mathrm{N}$.

Due to the uncertainties of surface flux estimation, it is not possible to reliably determine the oceanic heat transport from atmospheric data alone. The uncertainty in estimates of ocean heat transport from surface fluxes could be illustrated by carrying out the integration using the upper and lower limits from Fig. 7a; this uncertainty would become quite large as the integration proceeds toward the south, much larger than the error bars on the oceanic heat transport. On the other hand, the set of parameterizations used, based on modern surface flux data, is consistent with oceanic evidence and does not require adjustment. We still cannot be assured that each of the terms is individually correct, only that they are consistent with each other and with the oceanographic sections.

These are "local" parameterizations. For use with numerical models, it is still necessary to account separately for differences between local and gridpoint variables, as mentioned earlier.

\section{c. Available fields of air-sea interactions}

The density of ship observations in the Atlantic Ocean makes a higher resolution possible than with global fields (Bunker 1976). In the Bunker Climate Atlas of the North Atlantic Ocean, Isemer and Hasse (1985, 1987) gave $1^{\circ} \times 1^{\circ}$ monthly and annual wind and stress fields and also derived fields, such as the curl of stress. Bunker's treatment of stability and wind speed depen- 
dence was followed by Isemer and Hasse, but the transfer coefficient were adjusted to better correspond to experimental flux determinations (by eddy correlation and profiles) from the open ocean. The larger dataset now available in COADS suggested a reevaluation of the climate of the Atlantic and an extension of the study to the South Atlantic. A climate atlas of the Atlantic Ocean has been based on COADS using today's best available paramaterizations for the heat balance at the sea surface (Lindau 1997).

The fields of observations and air-sea fluxes from the Bunker dataset of the North Atlantic Ocean (Isemer and Hasse 1985, 1987) are publicly available from the Institut für Meereskunde, Universität Kiel (IfM); from the National Center for Atmospheric Research, Boulder, Colorado; and from the Woods Hole Oceanographic Institute. Fields of the COADS Climate Atlas of the Atlantic Ocean (Lindau 1997) are available on request from IfM.

\section{A need for further research into the inertial-dissipation method}

The inertial-dissipation method of estimating wind stress and sensible and latent heat fluxes at sea from measured wind, temperature, and humidity spectra allows data to be taken from ships, while the more direct eddy correlation method requires a stable platform that offers minimal flow distortion. Platforms suitable for eddy correlation measurements are few in number and are mainly in coastal or shallow waters, where the fluxes may differ from their values over the open ocean. The "inertial-dissipation" technique is being used more and more to estimate wind stress in meteorological and oceanographic experiments (Smith et al 1996), and as "sea truth" in the development of algorithms for wind stress estimation from satellite remote sensing.

The basis for this method is the well-known Kolmogoroff theory of locally isotropic turbulence. At sufficiently high Reynolds numbers there is a range of high wave numbers where the turbulence is statistically in equilibrium and uniquely determined by the parameters $\epsilon$ (dissipation of turbulent kinetic energy) and $v$ (viscosity). This state of equilibrium is universal. If the Reynolds number is sufficiently large, the energy spectrum in the subrange of wavenumbers $\mathrm{k}$ satisfying the condition $k_{e} \ll k \ll k_{d}$ (i.e. the wave number is very large compared to that of energy-containing eddies and small compared to that in the region of viscous dissipation) is independent of $v$ and is solely determined by one parameter $\epsilon$. Since in this subrange the inertial transfer of energy is the dominating factor, this will be called the inertial subrange (Hinze 1959, 184-186).

The theory results in the wind spectral energy being proportional to $\epsilon^{2 / 3} f^{-5 / 3} ; f$ is frequency. Hence, from measured spectral wind energy in the inertial subrange, the energy dissipation may be obtained, and from this, the generation of turbulent energy and the shear stress may

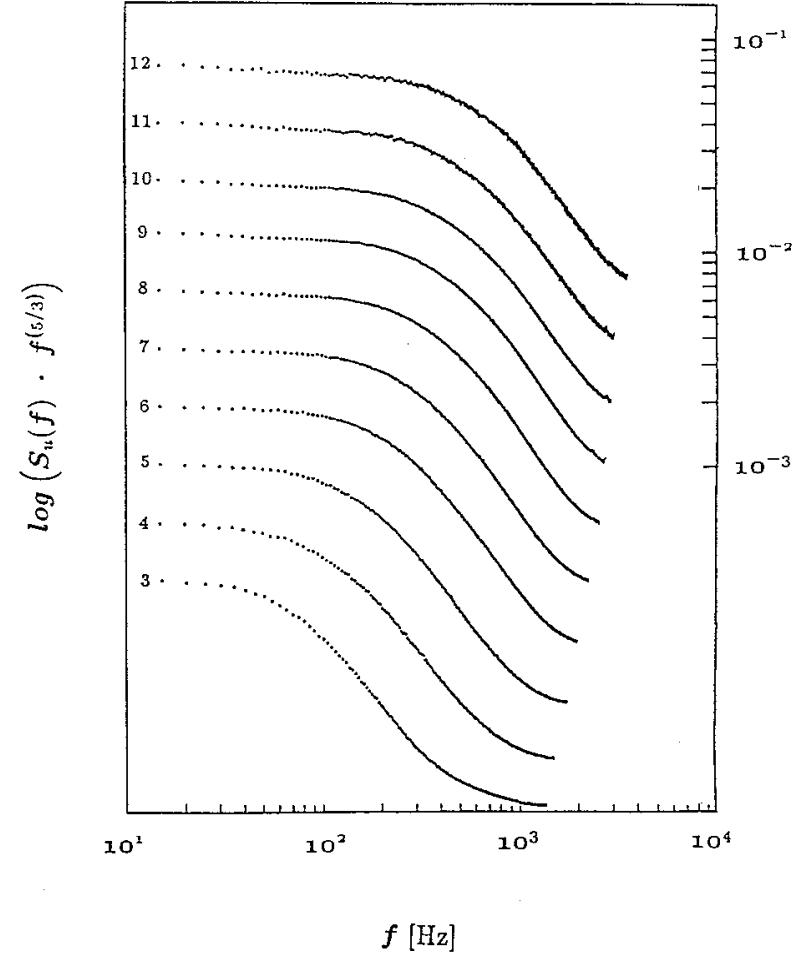

FIG. 8. Averaged downwind spectra grouped by wind speed from 3 to $12 \mathrm{~m} \mathrm{~s}^{-1}$. (From Neugum 1996.)

be inferred. Sensible and latent heat fluxes may be similarly inferred from temperature and humidity spectra.

Each group using the method has different sensors and uses slightly different methods to allow for imperfections in the theory and assumptions. Large and Pond (1981) "calibrated" their inertial-dissipation method with eddy correlation measurements at a stabilized platform and then analysed wind stress from ship data. Edson et al. (1991) and Smith et al. (1992) compared inertial-dissipation and eddy correlation wind stresses, colocated on a platform and also at a nearby ship. Yelland and Taylor (1996) and Yelland et al. (1997) found that an empirical "imbalance" term dependent on stratification and wind speed improves their results, and that corrections are also needed for the distortion of mean wind speed measured from ships; with these adjustments, their wind stress data support the use of (6).

Wucknitz (1979) has shown that the chain of theory and assumptions used in inertial-dissipation analysis is not as simple as thought in the beginning. There are two difficulties in meeting the requirements of the Kolmogoroff inertial subrange (Neugum 1996): 1) local isotropy is not fully reached; and 2) at low wind speeds, the "dissipation" range of the spectrum is not far enough removed from the spectral range of surface waves and boundary layer structures to provide a wide $f^{-5 / 3}$ spectral power law range (Fig. 8). At the suggestion of one of the authors (SDS), the International Commission on Dynamic Meteorology of the International 
Association of Meteorology and Atmospheric Physics has recommended a field intercomparison of such techniques.

\section{Summary and conclusions}

\section{a. Recommended coefficients for wind stress}

For large-scale and climatological applications, the local sea surface drag coefficient can be represented as a function only of wind speed and stability by (6), based on eddy correlation data. This is supported by the inertial-dissipation results of Anderson (1993) and of M. Yelland et al. (1997, manuscript submitted to J. Phys. Oceanogr.), and does not differ significantly from the result of Large and Pond (1981). Most other wind stress data are from coastal and shallow areas ( $\leq 30-\mathrm{m}$ depth), where higher values are found. The influence of stratification can be calculated from observed air-sea virtual temperature differences by iterative solution of empirical equations, or from look-up tables (e.g., Smith 1988).

Recent efforts have been directed at finding an explicit dependence of the drag coefficient on wave age. For studies of wave growth and of transient mesoscale events such as storms, it would be desirable to have a parameterization such as (5), but the precise form of the variability of the drag coefficient of the sea surface in natural wave fields is still uncertain. This is seen as a most important area for improvement of the description of air-sea momentum flux. A renewed effort to improve knowledge of energy input and dissipation in a sea state is necessary in order to better represent these terms in the otherwise already very successful modeling of waves and sea state.

\section{b. Recommended coefficients for evaporation and sensible heat flux}

The general concensus is that $C_{E N}$ has a value close to that of DeCosmo et al. (1996), who advocate a constant $C_{E N}(12)$. Their data are also consistent with a small rise of about $15 \%$ over the wind speed range. this ambiguity is a result of scatter inherent even in recent, carefully taken eddy flux measurements; $C_{H}$, which is difficult to measure precisely, is believed to have a value nearly equal to but slightly smaller than $C_{E}$. Isemer and Hasse (1987) selected a ratio $C_{H} / C_{E}=0.94$.

\section{c. Recommendations for surface flux calculation from COADS}

Lindau (1995a,b; 1997) has reexamined the interpretation of Beaufort wind forces and recomputed the surface heat flux of the Atlantic Ocean. With COADS, we recommend his parameterization of turbulent heat fluxes and of radiative fluxes since this gives integrated mean fluxes that are consistent with meridional fluxes from oceanographic sections at several latitudes. This lends confidence in the methods used, although it does not rule out the possibility that there may be compensating errors among the various terms. Consistency over a wide range of climates implies that the same methods can be applied to global climatological data.

DeCosmo et al. (1996) found that $C_{E N}$ increases only moderately, if at all, with wind speed. Based on the work of Bunker, which was done before direct measurements existed, Lindau (1997) took $C_{E N}$ to increase by about $30 \%$ between 5 - and $20-\mathrm{m} \mathrm{s}^{-1}$ wind speed, and on average Lindau's coefficients are slightly higher than those observed by DeCosmo et al. (see Figs. 3 and 4). For climatological calculations, the wind speed dependence may be of relatively minor concern as long as mean values are satisfactory. How important the dependence of $C_{E}$ on wind speed is for modeling weather and for climatological studies of annual cycles or shortterm events remains to be determined.

\section{d. A recommendation for tests of consistency of model-derived fluxes}

Because adjustments are needed for gridded (vs local) variables, because the model variables may have different physics from surface observations, and because numerical models use different methods to determine long- and shortwave radiation, separate tests of the consistency of model-derived surface fluxes with oceanic transport will be needed. If a number of years of data are available, the Atlantic Ocean between $30^{\circ} \mathrm{S}$ and $65^{\circ} \mathrm{N}$ can be used as an area to test the consistency of modelderived fluxes against available climatological and oceanographic results; the COADS analysis of Lindau (1997) serves as an example. Also, in the annual average, the net heat flux to or from the global oceans should nearly balance. By tuning the coefficients in the flux formulas within the range of their uncertainty, consistent results can be achieved in a particular application that are still compatible with experimental results for the various components of the surface heat flux.

The drag coefficients recommended above are valid at the local scale. When these are applied to modeled winds, the characteristics of "surface wind" need to be considered, and in particular, subgrid-scale variability must be considered separately.

Acknowledgments. The authors thank J. DeCosmo, S. K. Gulev, S. A. Josey, R. Lindau, A. Neugum, P. K. Taylor, and M. Yelland for making available results of recent research. The helpful comments of the reviewers are appreciated.

\section{REFERENCES}

Aagaard, K., and P. Greisman, 1975: Towards new mass and heat budgets for the Arctic Ocean. J. Geophys. Res., 80, 3821-3827.

Anderson, R. J., 1993: A study of wind stress and heat flux over the open ocean by the inertial dissipitation method. J. Phys. Oceanogr., 23, 2153-2161. 
Berkowicz, R., and L. P. Prahm, 1982: Evaluation of the profile method for estimation of surface fluxes of momentum and heat. Atmos. Environ., 16, 2809-2819.

Bortkovskii, R. S., 1987, Air-Sea Exchange of Moisture during Storms. Reidel, 194 pp.

Bradley, E. F., P. A. Coppin, and J. S. Godfrey, 1991: Measurements of sensible and latent heat flux in the western equatorial Pacific Ocean. J. Geophys. Res., 96, 3375-3389.

Bryden, H. L., and M. M. Hall, 1980: Heat transports across $25^{\circ} \mathrm{N}$ in the Atlantic Ocean. Science, 207, 884-886.

Bumke, K., 1995: Spatial scales of surface wind observations and analysed wind fields over the North Atlantic Ocean. J. Mar. Syst., 6, 67-75.

Bunker, A. F., 1976: Computations of surface energy flux and annual air-sea interaction cycles of the North Atlantic Ocean. Mon. Wea. Rev., 104, 1122-1140.

Charnock, H., 1981: Air sea interaction. Evolution of Physical Oceanography, B. A. Warren and C. Wunsch, Eds., The MIT Press, 482-503.

DeCosmo, J., K. B. Katsaros, S. D. Smith, R. J. Anderson, W. A. Oost, K. Bumke, and H. Chadwick, 1996: Air-sea exchange of sensible heat and water vapor over whitecap sea states. J. Geophys. Res., 101, 12 001-12016.

Dobson, F. W., 1981: Review of reference height for and averaging time of surface wind measurements at sea. Marine Meteorology and Related Oceanographic Activities Rep. 3, World Meteorology Organization, Geneva, Switzerland, 64 pp. [Available from WMO, 41 Avenue Giuseppe Motta, CH-1211, Geneva, Switzerland.]

— W. Perrie, and B. Toulany, 1989: On the deep-water fetch laws for wind-generated surface gravity waves. Atmos.-Ocean, 27, 210-236.

— lationship between wind stress and sea state in the open ocean in the presence of swell. Atmos.-Ocean, 32, 237-256.

Donelan, M. A., J. Hamilton, and W. H. Hui, 1985: Directional spectra of wind-generated waves. Proc. Roy. Soc. London, A315, 509562.

_ F. W. Dobson, S. D. Smith, and R. J. Anderson, 1993: On the dependence of sea surface roughness on wave development. $J$. Phys. Oceanogr., 23, 2143-2149.

Dunckel, M., L. Hasse, L. Krugermeyer, D. Schreiver, and J. Wucknitz, 1974: Turbulent fluxes of momentum, heat and water vapor in the atmospheric surface layer at sea during ATEX. Bound.Layer Meteor., 6, 81-106.

Edson, J. B., C. W. Fairall, S. E. Larsen, and P. G. Mestayer, 1991: A study of the inertial-dissipation method for computing air-sea fluxes. J. Geophys. Res., 96, $10689-10711$.

Esbensen, S. K., and M. J. McPhaden, 1996: Enhancement of tropical ocean evaporation and sensible heat flux by atmospheric mesoscale systems. J. Climate, 9, 2307-2325.

Frenzen, P., and C. A. Vogel, 1995: On the magnitude and apparent range of variation of the von Karman constant in the atmospheric surface layer. Bound.-Layer Meteor., 72, 371-392.

Gilman, C., and C. J. R. Garrett, 1994: Heat flux parameterizations for the Mediterranean Sea: The role of atmospheric aerosols and constraints from the water budget. J. Geophys. Res., 99, 51195134.

Gulev, S. K., 1994: Influence of space-time averaging on the oceanatmosphere exchange estimates in the North Atlantic midlatitudes. J. Phys. Oceanogr., 24, 1236-1255.

- , 1995: Long-term variability of sea-air heat transfer in the North Atlantic Ocean. Int. J. Climatol., 15, 825-852.

- 1997: Climatologically significant effects of space-time averaging in the North Atlantic flux fields. J. Climate, 11, 27432763.

_ , and V. A. Tikhonov, 1989: Interannual variations of the ocean heat balance and meridional heat transport. Atmos.-Ocean, 7, 332-341.

Hanawa, K., and Y. Toba, 1987: Critical examination of estimation methods of long-term mean air-sea heat and momentum transfers. Ocean-Air Int., 1, 79-93.

Hasse, L., M. Grünewald, J. Wucknitz, M. Dunckel, and D. Schreiver, 1978: Profile-derived turbulent fluxes in the surface layer under disturbed and undisturbed conditions during GATE. "Meteor" Forschchungsergeb., B13, 24-40.

Hasselmann, K., and Coauthors, 1973: Measurements of wind-wave growth and swell decay during the Joint North Sea Wave Project (JONSWAP). Dtsch. Hydrogr. Z., 12, 95 pp.

Hastenrath, S., and P. J. Lamb, 1978: Heat Budget Atlas of the Tropical Atlantic and Eastern Pacific Oceans. University of Wisconsin Press, 104 pp.

Hinze, J. O., 1959: Turbulence. McGraw-Hill, 586 pp.

Holfort, J., 1994: Großräumige Zirkulation und meridoanale Transporte im Südatlantik. Ber. Inst. Meereskd. Kiel, 260, 96 pp.

Isemer, H.-J., and L. Hasse, 1985: The Bunker Climate Atlas of the North Atlantic Ocean. Vol. 1, Observations, Springer-Verlag, $218 \mathrm{pp}$.

, and - 1987: The Bunker Climate Atlas of the North Atlantic Ocean. Vol. 2, Air Sea Interactions, Springer-Verlag, $252 \mathrm{pp}$.

— scale air-sea energy flux parameterizations by direct estimates of ocean heat transport. J. Climate, 2, 1173-1184.

Josey, S. A., E. C. Kent, and P. K. Taylor, 1995: Seasonal variations between sampling and classical mean turbulent heat flux estimates in the North Atlantic. Ann. Geophys., 13, 1054-1064.

Kagan, B. A., 1995: Ocean-Atmosphere Interaction and Climate Modelling. Cambridge University Press, 377 pp.

Karger, U., 1995: Kuesteneinfluss auf mittlere Bodenwindgeschwindigkeiten über der Ostsee. Ph.D. thesis, Universität Kiel, 82 pp.

Kaufeld, L., 1981: The development of a new Beaufort equivalent scale. Meteor. Rundsch., 34, 17-23.

Large, W. G., and S. Pond, 1981: Open ocean momentum flux measurements in moderate-to-strong winds. J. Phys. Oceanogr., 11, 324-336.

Lindau, R., 1995a: A new Beaufort equivalent scale. Ber. Inst. Meeresk. Kiel, 265, 232-252.

_ 1995 b: Time dependent calibration of marine Beaufort estimates using individual pressure differences. Ber. Inst. Meeresk. Kiel, 265, 253-269.

- 1997: The COADS Climate Atlas of the Atlantic Ocean. Springer-Verlag, in press.

Liu, W. T., K. B. Katsaros, and J. A. Businger, 1979: Bulk parameterization of the air-sea exchange of heat and water vapor including the molecular constraints at the interface. J. Atmos. Sci., 36, 1722-1735.

Malevsky, S. P., G. V. Girduk, and B. Egorov, 1992: Radiation Balance of the Ocean Surface. Hydrometeoizdat, $148 \mathrm{pp}$.

Miller, M. J., A. C. M. Beljaars, and T. N. Palmer, 1992: The sensitivity of the ECMWF model to the parameterization of evaporation from the tropical oceans. J. Climate, 5, 418-434.

Neugum, A., 1996: Systematic influences in the determination of stress at sea with the so-called "dissipation" technique (in German). Ber. Inst. Meereskd. Kiel, 279, 110 pp.

Panofsky, H. A., and J. A. Dutton, 1984: Atmospheric Turbulence. Wiley-Interscience, $397 \mathrm{pp}$.

Perrie, W., and B. Toulany, 1990: Fetch relations for wind-generated waves as a function of wind-stress scaling. J. Phys. Oceanogr., 20, 1666-1681.

- and - 1995: Relating friction velocity to spectral wave parameters. J. Phys. Oceanogr., 25, 266-279.

- and L. Wang, 1995: A coupling mechanism for wind and waves. J. Phys. Oceanogr., 25, 615-630.

Peterson, E. W., and L. Hasse, 1987: Did the Beaufort scale or the wind climate change? J. Phys. Oceanogr., 17, 1071-1074.

Reed, R. K., 1977: On estimating insolation over the ocean. J. Phys. Oceanogr., 7, 482-485. 
Smith, P. C., and J. I. MacPherson, 1987: Cross-shore variations of near-surface wind velocity and atmospheric turbulence at the land-sea boundary during CASP. Atmos.-Ocean, 25, 279303.

Smith, S. D., 1980: Wind stress and heat flux over the ocean in gale force winds. J. Phys. Oceanogr., 10, 709-726

— 1988: Coefficients for sea surface wind stress, heat flux, and wind profiles as a function of wind speed and temperature. $J$. Geophys. Res., 93, $15467-15472$.

- 1989: Water vapor flux at the sea surface. Bound.-Layer Meteor., 47, 277-293.

_ , and Coauthors, 1992: Sea surface wind stress and drag coefficients: The HEXOS results. Bound.-Layer Meteor., 60, 109142

C. W. Fairall, G. L. Geernaert, and L. Hasse, 1996: Air-sea fluxes: 25 years of progress. Bound.-Layer Meteor., 78, 247290.

Speer, K. G., J. Holfort, T. Reynaud, and G. Siedler, 1997: South Atlantic heat transport at $11^{\circ} \mathrm{S}$. The South Atlantic: Present and Past Circulation, G. Wefer and G. Siedler, Eds., Springer, in press.

Wippermann, F., 1972: A note on the parameterization of the largescale wind stress at the sea surface. Beitr. Phys. Atmos., 45, 260-266.

Wucknitz, J., 1979: The influence of anisotropy on stress estimation by the indirect dissipation method. Bound.-Layer Meteor., 17, 119-131.

Wunsch, C., 1984: An eclectic Atlantic Ocean circulation model. Part 1: The meridional flux of heat. J. Phys. Oceanogr., 14, 17121733.

Yelland, M., and P. K. Taylor, 1996a: Wind stress measurements from the open ocean. J. Phys. Oceanogr., 26, 541-558. 